Article

\title{
An Experimental Study on the Performance of Corrugated Cardboard as a Sustainable Sound-Absorbing and Insulating Material
}

\author{
Chun-Won Kang ${ }^{1}\left(\mathbb{D}\right.$, Mina K. Kim ${ }^{2} \mathbb{D}$ and Eun-Suk Jang ${ }^{1,3, * \mathbb{D}}$ \\ 1 Department of Housing Environmental Design and Research Institute of Human Ecology, \\ College of Human Ecology, Jeonbuk National University, Jeonju 54896, Korea; kcwon@jbnu.ac.kr \\ 2 Department of Food Science \& Human Nutrition and Research Institute of Human Ecology, \\ College of Human Ecology, Jeonbuk National University, Jeonju 54896, Korea; minakim@jbnu.ac.kr \\ 3 R\&D Center, Sambo Scientific Co., Ltd., Seoul 07528, Korea \\ * Correspondence: esjang@sambosc.com
}

check for updates

Citation: Kang, C.-W.; Kim, M.K.; Jang, E.-S. An Experimental Study on the Performance of Corrugated Cardboard as a Sustainable Sound-Absorbing and Insulating Material. Sustainability 2021, 13, 5546. https://doi.org/10.3390/su13105546

Academic Editor: Shervin Hashemi

Received: 8 April 2021

Accepted: 14 May 2021

Published: 16 May 2021

Publisher's Note: MDPI stays neutral with regard to jurisdictional claims in published maps and institutional affiliations.

Copyright: (c) 2021 by the authors. Licensee MDPI, Basel, Switzerland. This article is an open access article distributed under the terms and conditions of the Creative Commons Attribution (CC BY) license (https:// creativecommons.org/licenses/by/ $4.0 /)$.

\begin{abstract}
The continuing development of industrialization and increasing population density has led to the emergence of noise as an increasingly common problem, requiring various types of sound absorption and insulation methods to address it. Meanwhile, the recycling of resources to ensure a sustainable future for the planet and mankind is also required. Therefore, this study investigates the potential of corrugated cardboard as a resource for noise reduction. The sound absorption and insulation performance of non-perforated corrugated cardboard (NPCC) were measured, and modified corrugated boards were fabricated by drilling holes either through the surface of the corrugated board alone or through the corrugated board in its entirety. The sound-absorption/insulation performance both of perforated corrugated cardboard (PCC) and perforated corrugated cardboard with multi-frequency resonators (PCCM) were measured using the transfer function method and the transmission matrix method. To determine the effectiveness of NPCC, PCC, and PCCM in noise reduction, the sound pressure level was analyzed by applying it to a home blender. The results showed PCCM's sound absorption and insulation performance to be excellent. On the basis of these findings, we propose the use of PMMC as an eco-friendly noise-reduction material.
\end{abstract}

Keywords: eco-friendly sound-absorbing material; corrugated cardboard; perforated corrugated cardboard; sound-absorption coefficient; sound transmission loss; transfer function method; transfer matrix method; multi-frequency resonator

\section{Introduction}

Because Republic of Korea is a country with small land mass and high population density, apartment housing is common [1]. Noise complaints in these apartment complexes are an unavoidable reality [2]. According to the National Noise Information System (NOISEINFO), a government agency that monitors noise problems in the country, the number of reported noise-related problems has increased exponentially, from 1829 cases in 2012 to 10,142 cases in 2019 [3].

Overall noise level reduction is necessary for maintaining an agreeable sound environment [4]. Blocking or reducing noise through sound absorption and sound insulation is a mainstream method [5]. Accordingly, a significant amount of research has been conducted in order to identify materials with excellent sound absorption and sound insulation properties [6,7]. Sound-absorbing materials typically include one or more components from porous materials [8], plate or membrane vibration materials [9], or resonators [10,11].

Traditionally, the most important metric by which a potential sound-absorbing material is assessed is its absorption ability. However, while the materials typically relied on for indoor acoustic control are typically derived from petroleum [12], recent years have 
seen a new focus on the utilization of sustainable green materials, including agricultural by-products, to fulfill this function [13-15]. In this spirit, a wide range of studies have been conducted of eco-friendly sound-absorption materials such as rice straw [16], rice husks [17], palm fibers [18], giant reeds [19], egg cartons [20], and wood paper [21].

Corrugated cardboard is a bio-degradable, eco-friendly paper material that is inexpensive and robust in relation to its weight [22]. Its thickness and empty middle space make it a useful sound insulating material [23]. It can be used as a resonance sound-absorbing material either by perforating only the surface of the corrugated board or by penetrating the entire thickness of the corrugated board. Its sound-absorption properties for specific frequency bands can be enhanced by modifying hole size and depth [24]. Corrugated cardboard can also be used as an interior building material and, when discarded, can be reused for pulp or paper [25]. Corrugated cardboard is known for its utility as a building material $[25,26]$, and some studies have suggested the potential of hydrophobic treatment to avoid moisture absorption and further expand its versatility $[27,28]$. Moreover, it may act as a flame retardant, improving building safety [29].

With an eye toward these benefits, we set out to determine whether corrugated cardboard could be utilized as a sustainable noise-reducing building material.

Berardi and Iannace [30] measured cardboard's sound-absorption coefficient by inserting its veins in a direction parallel to the impedance tube. This resulted in excellent sound-absorption performance at medium and high frequencies but poor performance at low frequencies below $400 \mathrm{~Hz}$. In short, while the material performed well in the veins of the cardboard direction, as a practical matter, it is not easy to use the material in this way.

Kang and Seo [31] investigated changes to the resonant frequency of the cardboard as a function of changes to the aperture ratio. They found no significant changes but reported that sound absorption at a specific frequency was significantly increased by perforations of a certain depth and size. Kang et al. [32] reported that applying porous polyurethane foam attached to a corrugated cardboard to a household blend reduced the sound-absorption coefficient and sound transmission loss. Polyurethane foam, however, is not an eco-friendly sound-absorbing material, and sound-absorbing performance may be improved with additional research into the corrugated board itself.

This study developed a natural sound absorber using triple-layer-corrugated cardboard whose inner surface layers were pierced with holes to enhance its resonance soundabsorbing properties. Three types of corrugated cardboard were prepared: non-perforated corrugated cardboard (NPCC), perforated corrugated cardboard (PCC), and perforated corrugated cardboard with multi-frequency resonator (PCCM). The sound absorption and insulation properties of each of these types were then measured using the transfer function method and the transmission matrix method.

To test these corrugated sound-absorbing materials, they were applied to the use case of home blenders. A home blender was selected as a noise generator since it is one of the most common noise-producing household appliances [33].

The noise level of the blender's rotor was first analyzed. After this, a Helmholtz resonator actively formed in the thickness direction corresponding to the frequency characteristics of the noise source was created on the surface of the corrugated cardboard.

An additional cavity layer was installed between the single-resonator corrugated cardboard and the NPCC, while part of the surface perforation was connected to the rear layer in order to create a multi-resonator with multiple frequencies. The noise reduction effect on the blender was evaluated by measuring and comparing the sound-absorption rate, acoustic transmission loss, and noise level of the fabricated single-resonator and multi-resonator-perforations in relation to hole diameter and perforation ratio. 


\section{Materials and Methods}

\subsection{Sample Preparation}

As shown in Figure 1, triple-walled, seven-layer corrugated cardboard with $1800 \mathrm{~g} / \mathrm{m}^{2}$ base weight and $15.0 \mathrm{~mm}$ thickness was sourced from a Korean market (Daeyoung Packaging Co, Ltd., Ansan-si, Korea).

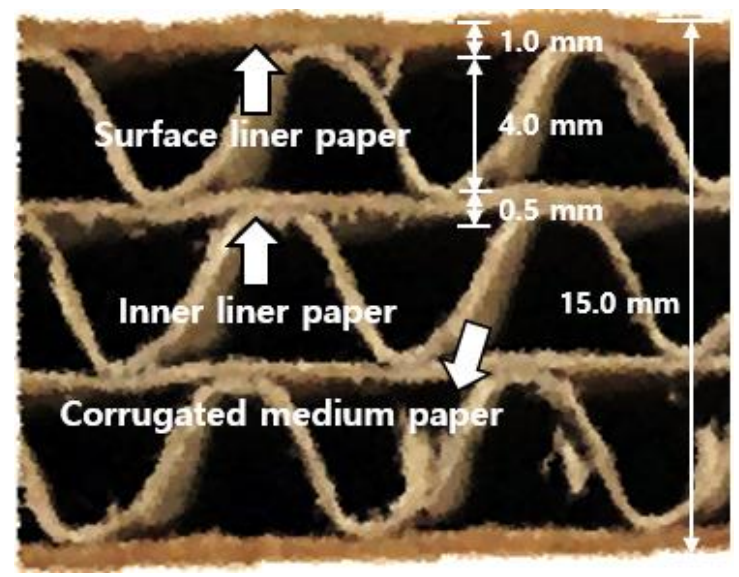

Figure 1. Triple-wall corrugated cardboard structure.

In this study, three types of corrugated cardboard were used as sound absorbers. Figure 2 shows the respective structures of the three corrugated cardboard types, while Figure 3 shows application of the cardboard to the blender. NPCC denotes non-perforated corrugated cardboard (Figure 3a). PCC denotes single-resonance sound-absorbing corrugated cardboard whose surface liner paper was pierced with $2.3 \mathrm{~mm}$ diameter holes at $14 \mathrm{~mm}$ intervals (Figure $3 \mathrm{~b}$ ).

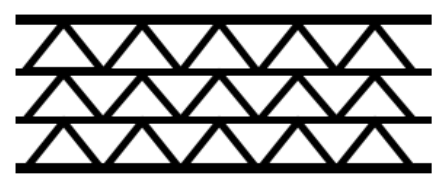

(a)

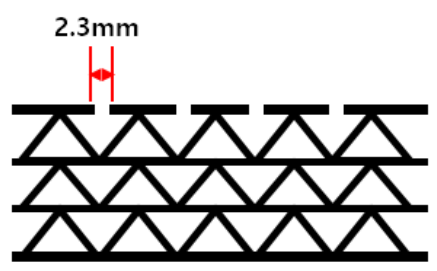

(b)

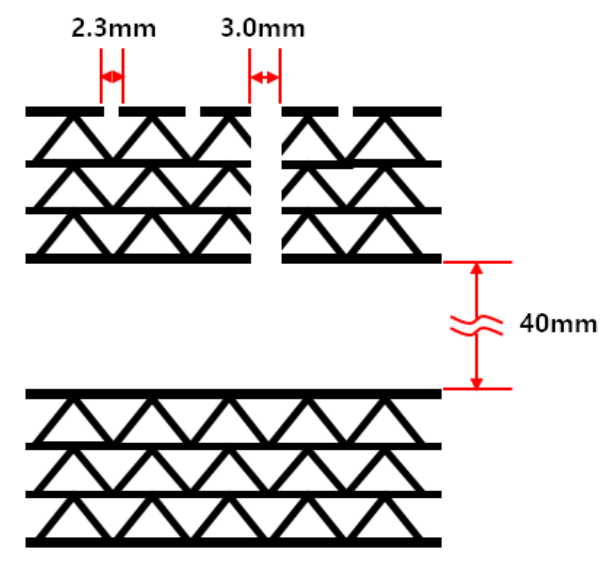

(c)

Figure 2. Three corrugated cardboard type structures. (a): NPCC, (b): PCC and, (c): PCCM.

PCCM denotes PCC with additional $3.0 \mathrm{~mm}$ diameter holes $(1 / 4$ of the number of $2.3 \mathrm{~mm}$ diameter holes). The $3.0 \mathrm{~mm}$ diameter holes pierced all 7 layers of the corrugated cardboard. There was a $4 \mathrm{~cm}$ air cavity at the back where we added NPCC (Figure 3c).

Resonance occurs at different frequencies depending on perforated hole diameter, surface liner paper thickness, perforated hole area, and distance from the inner liner paper.

The resonance sound-absorption frequency was calculated as follows:

$$
\begin{gathered}
f_{0}=c / 2 \pi(G / V)^{0.5} \\
G=s / l e
\end{gathered}
$$




$$
l e=l+\delta
$$

where $c$ : sound velocity; $G$ : neck conductivity; $V$ : cavity volume; s: neck surface area; le: effective neck length; $l$ : neck length; and $\delta$ : end correction $(\fallingdotseq 0.8 \mathrm{~d})$

Therefore,

$$
f_{0}=c / 2 \pi(s / V(1+\delta))^{0.5}
$$

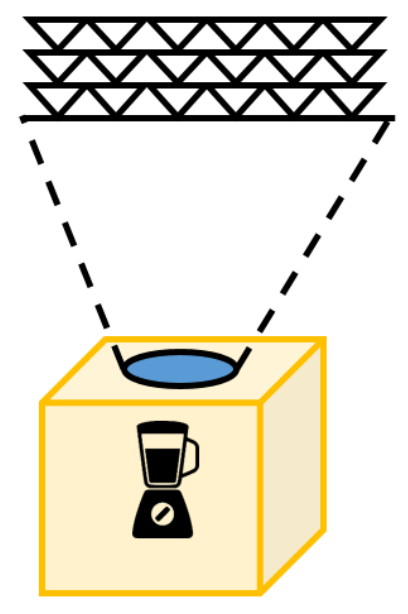

(a)

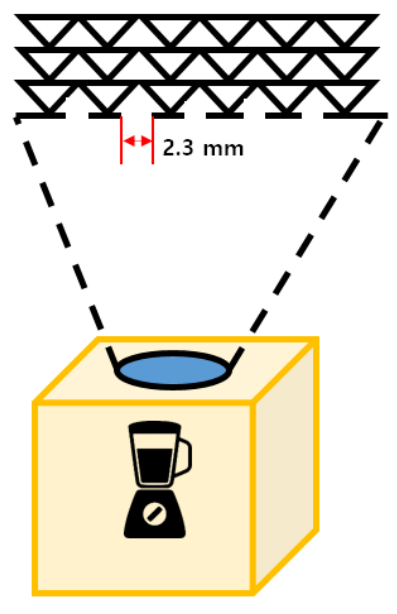

(b)

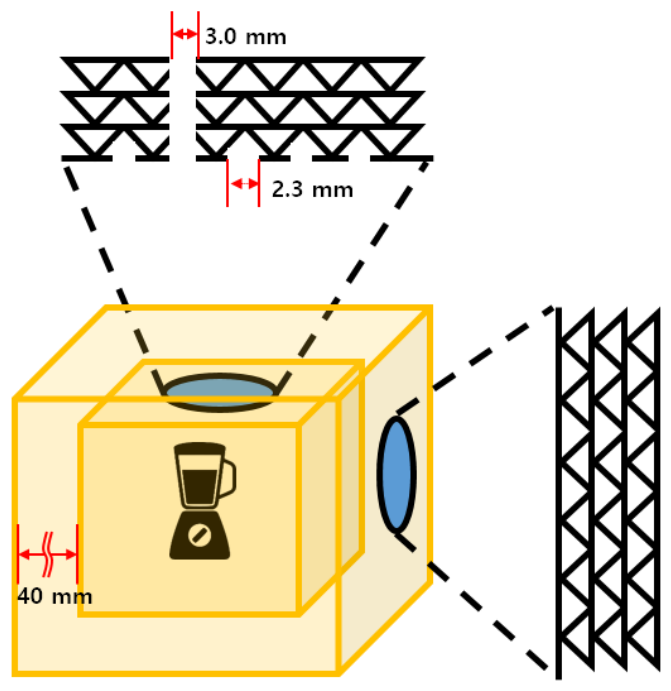

(c)

Figure 3. Three types of corrugated cardboard types for sound-absorbing materials applied to the blender. (a): NPCC, (b): PCC, and (c): PCCM.

\subsection{Measurement of Sound-Absorption Coefficient Using Transfer Function Method}

The sound-absorption coefficient (SAC) of the NPCC, PCC, and PCCM was measured using a B\&K type 4206 impedance tube according to ISO 10534-2 [34] (Figure 4). We additionally calculated the noise-reduction coefficient (NRC) as the average of the soundabsorption rates of 200,500, 1000, and $2000 \mathrm{~Hz}$.

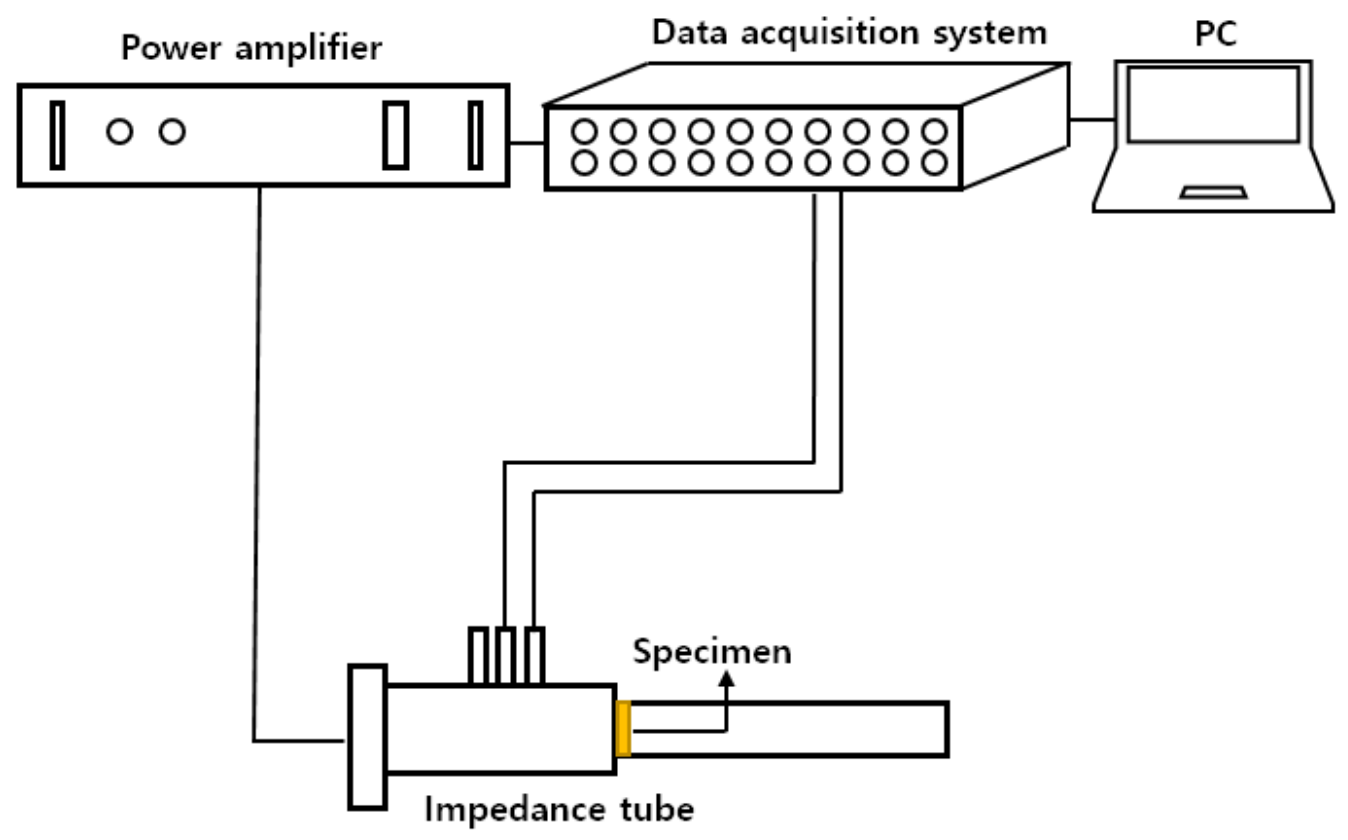

Figure 4. Schematic for B\&K type 4206 impedance tube used to measure SAC. 
Specimens were cut into $29 \mathrm{~mm}$ diameter pieces and inserted into an impedance tube. We added silicon O-rings to prevent experimental errors due to gaps between the sample and the wall of the impedance tube. SAC was measured in the $100-6400 \mathrm{~Hz}$ frequency range. Temperature, relative humidity, and air pressure were $25.8{ }^{\circ} \mathrm{C}, 53 \%$, and $1012.00 \mathrm{hPa}$, respectively. Sound velocity, air density, and acoustic impedance were $346.62 \mathrm{~m} / \mathrm{s}, 1.177 \mathrm{~kg} / \mathrm{m}^{3}$, and $408.0 \mathrm{~Pa} /(\mathrm{m} / \mathrm{s})$, respectively.

\subsection{STL Measurements Using Transmission Matrix Method}

Sound transmission loss (STL), the ratio of the difference between incident sound energy to the material and transmitted sound energy to the material, represents the material's sound insulation performance. In this study, STL was measured in the $100-6400 \mathrm{~Hz}$ frequency band by the transmission matrix method according to ASTM E-2611 [35], using a B\&K type 4206-T impedance tube to measure acoustic transmission loss (Figure 5). Temperature, relative humidity, and air pressure during measurement were $26.3^{\circ} \mathrm{C}, 50 \%$, and $1010.0 \mathrm{hPa}$, respectively.

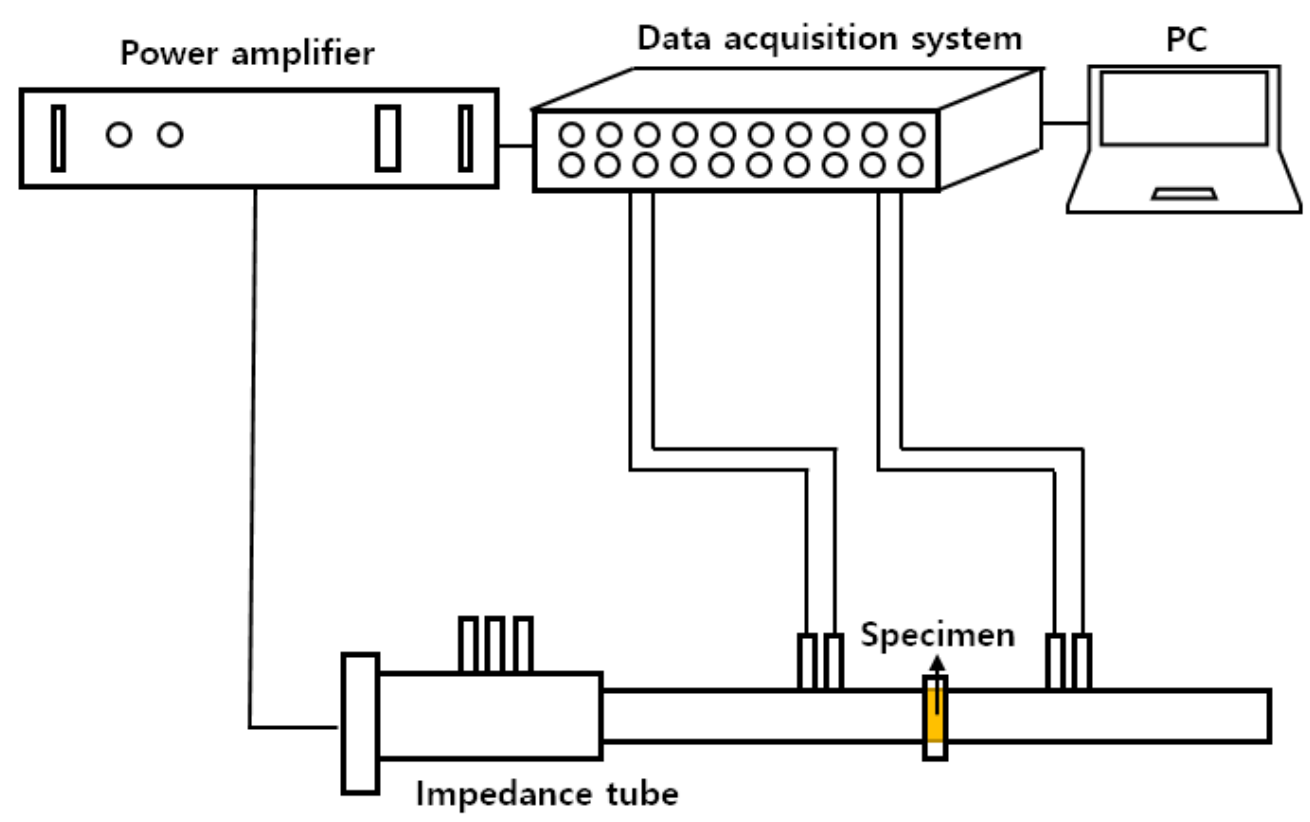

Figure 5. Schematic for B\&K 4206-T impedance used to measure STL.

\subsection{Sound Pressure Level Analysis}

To verify the actual noise reduction effect, we fabricated a cover using NPCC, PCC, and PCCM and applied this to the blender. First, we performed a sound pressure level analysis. Sound pressure level was measured using a B\&K type 2250 handheld sound analyzer in the $63-16,000 \mathrm{~Hz}$ frequency range with a $1 / 3$ octave analyzer. Sound pressure level can be measured from $63 \mathrm{~Hz}$. However, there is an experimental error due to noise generation below $50 \mathrm{~Hz}$; therefore, it was measured at frequencies above $100 \mathrm{~Hz}[33,34]$. Sound pressure was measured approximately $1 \mathrm{~m}$ from the top of the blender, and the sound pressure level is given as the average of the measured values over $20 \mathrm{~s}$. At the blender's maximum power, the maximum noise peak was in the $1-2 \mathrm{kHz}$ frequency band. Using this information, the resonance cover was optimized for the $1-2 \mathrm{kHz}$ frequency band. The blender was enclosed with the NPCC, PCC, and PCCM covers, and noise levels measured. Temperature, relative humidity, and air pressure during measurements were $28.7^{\circ} \mathrm{C}, 54 \%$, and $1017.2 \mathrm{hPa}$, respectively. 


\section{Results and Discussion}

\subsection{SAC Results from Transfer Function Method}

Figure 6 shows the SAC for NPCC, PCC, and PCCM in the 100-6400 Hz frequency range measured by impedance tube. The average SAC and NRC of NPCC were 0.062 (SD 0.010) and 0.055 (SD 0.012), respectively. This indicates almost no sound absorption. The average SAC and NRC of PCC were 0.331 (SD 0.009) and 0.346 (SD 0.007), respectively. The average SAC and NRC of PCCM were 0.362 (SD 0.017) and 0.423 (0.009), respectively.

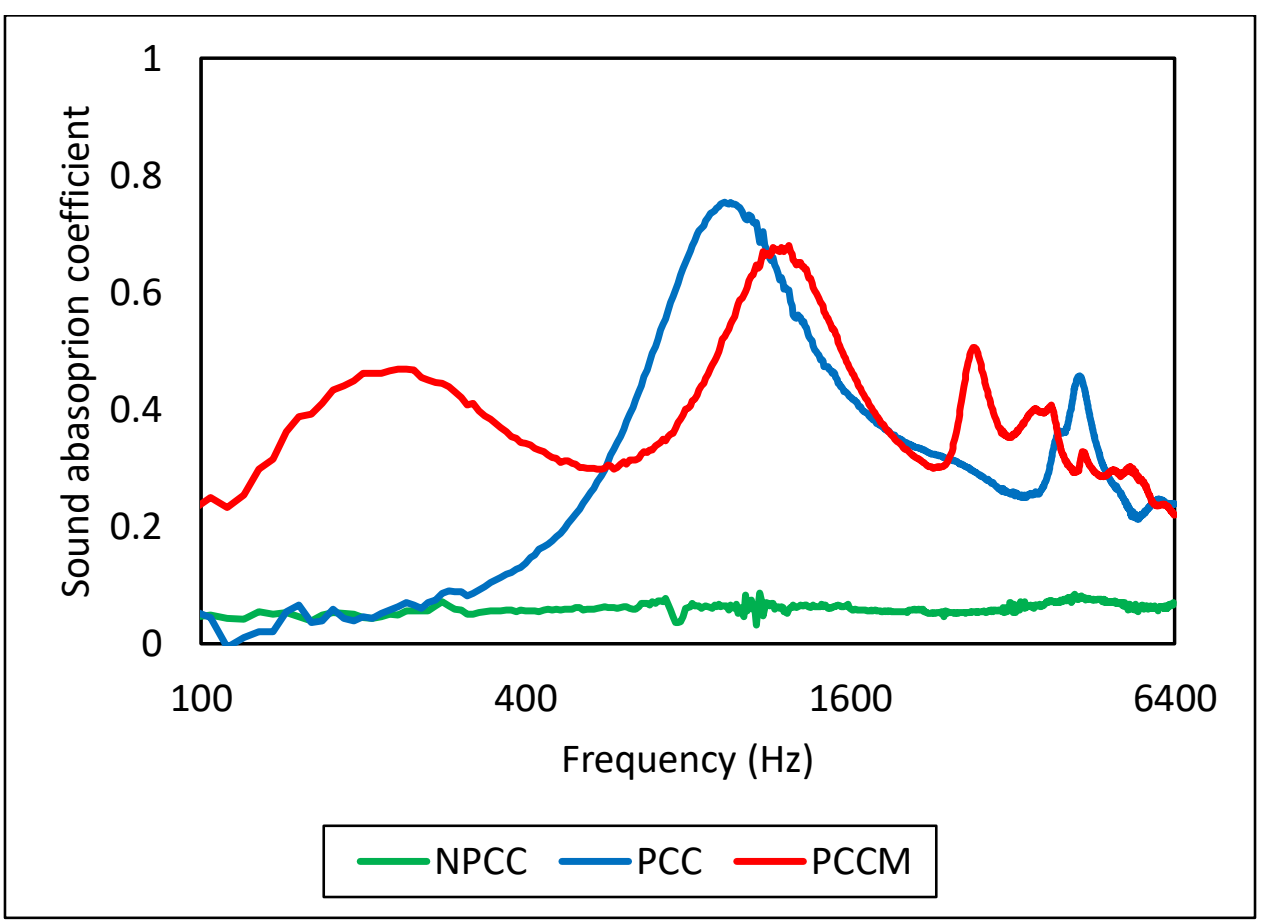

Figure 6. SAC results for NPCC, PCC, and PCCM.

As shown in Figure 2b, the PCC's void volume between the perforated surface liner paper and the inner liner paper becomes a single resonator. This is why it can resonate at specific frequencies.

The theoretical resonance frequency of PCC calculated from Equation 4 was $1102 \mathrm{~Hz}$. As shown in Figure 6, the resonance frequency of the PCC obtained experimentally was $936 \mathrm{~Hz}$. As Figure 2c shows, the PCCM's void volume is equal to that of the PCC, plus additional void volume between the corrugated cardboard and the rear space. This means that resonance occurs in two places, at 380 and $1050 \mathrm{~Hz}$. The theoretically calculated resonance frequency and experimentally measured resonance frequency were little bit different. The cause of such an error is that the corrugated cardboard does not only absorb sound by resonance, but an effect due to weak plate vibration may be added. In addition, in this study, since the hole was drilled by the experimenter, not by a machine such as $\mathrm{CNC}$, the hole size may not be constant; therefore, the frequency mismatch can be regarded as an experimental error.

As a result, the average SAC of the PCC increased approximately 5 times more than that of the NPCC, while the NRC of the PCC increased approximately 6 times more than that of the NPCC. In addition, the PCC had peak values of SAC, which were 0.754 at $936 \mathrm{~Hz}$ and 0.457 at $4264 \mathrm{~Hz}$. The SAC of the PCC was significantly increased at a specific frequency.

The average SAC of the PCCM was similar to that of the PCC, but the NRC of the PCCM increased approximately 1.2 times more than that of the PCC. The SAC peak values for the PCCM were 0.680 at $1232 \mathrm{~Hz}, 0.628$ at $2704 \mathrm{~Hz}$, and 0.469 at $240 \mathrm{~Hz}$. The PCCM is a multi-resonator and showed peak SAC values at various frequencies. 
Compared with other NRC natural fiber composite board (Bagasse: 0.32, Bamboo: 0.35, Banana 0.40, Coir of 0.29, Corn: 0.36) [36], the PCCM demonstrated higher soundabsorption capabilities.

We also compared the sound-absorption performance against Wooden MPP (microperforated panels), which are an eco-friendly sound-absorbing material in wide use. We extracted raw data for the sound-absorbing graph result of wooden MPP with holes of $2 \mathrm{~mm}$ in diameter and $10 \mathrm{~mm}$ intervals in a $5 \mathrm{~mm}$ wooden board and the rear air cavity set to $50 \mathrm{~mm}$ from the previous study [37] using Engauge Digitzer software [38], and compared the performance of this material with our cardboard. In addition, we added to compare with parallel direction of NPCC from Beradi et al. [27].

As shown Figure 7, PCC's SAC absorbed sound better over $680 \mathrm{~Hz}$ than Wooden MPP, and PCCM generally performed better at sound absorption than Wooden MPP, with the exception of the $400-600 \mathrm{~Hz}$ range. The wooden MPP had a rear space of $50 \mathrm{~mm}$, while that of the PMCC was $40 \mathrm{~mm}$. Were the space behind the PCC and PCCM to be further increased, the SAC at low frequencies might increase even more.

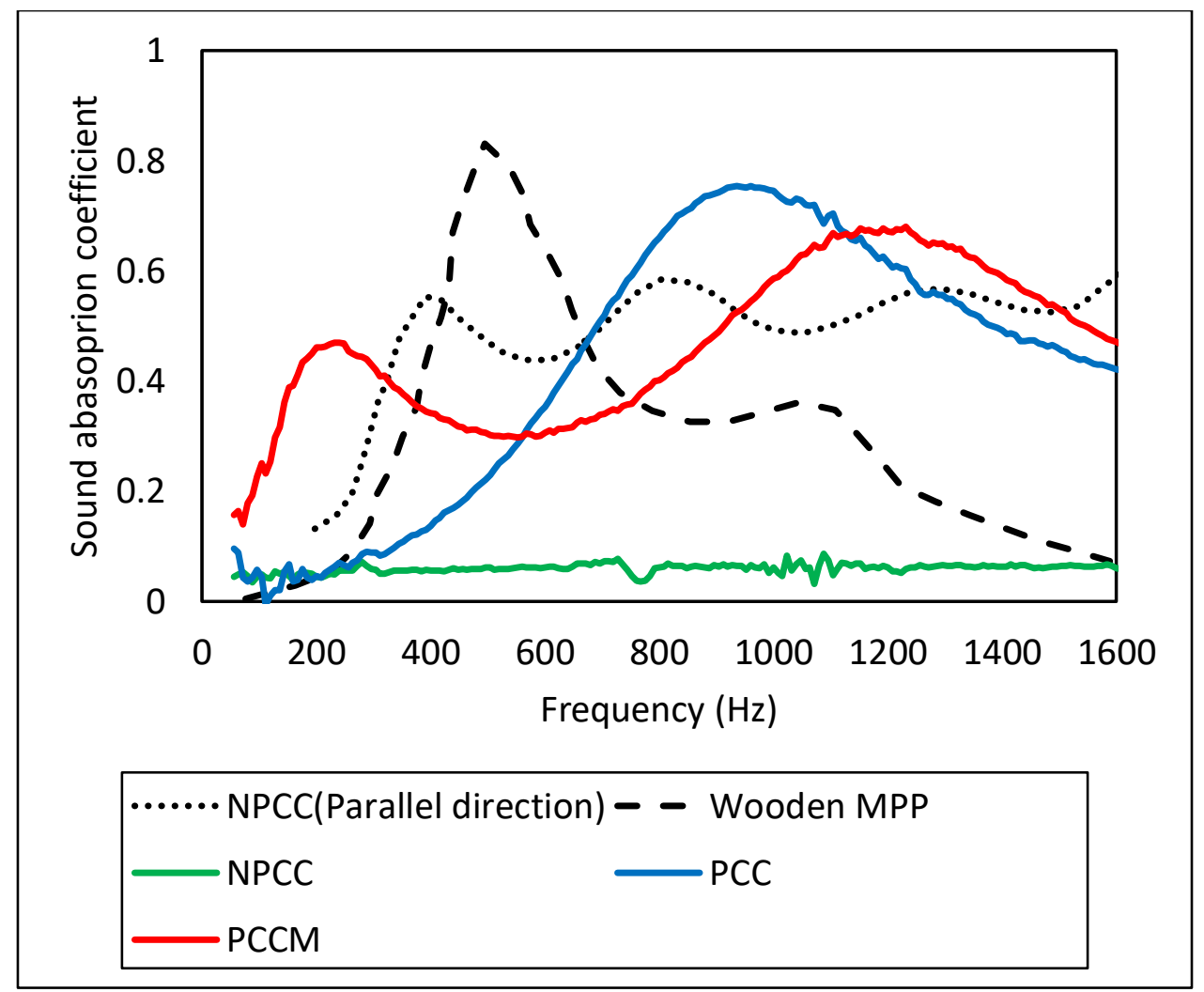

Figure 7. Compared SAC results for Wooden MPP from Song et al. [37], NPCC (Parallel direction) from Berardi et al. [27], NPCC, PCC, and PCCM from this work.

PMCC generally performed better at sound absorption than parallel direction of NPCC from Beradi et al. [27], with the exception of the 320-940 Hz range.

In sum, PCC and PMCC did not perform worse than Wooden MPP and parallel direction of NPCC. Corrugated cardboard is cheaper than wooden boards, lighter, easier to install, and easier to recycle. In addition, parallel direction of NPCC is not easy to use practically as sound-absorption material. Therefore, PCC's and PMCC's many advantages make them ideal environmentally friendly sound-absorbing materials.

In sum, PCC and PCCM did not perform worse than Wooden MPP. Corrugated cardboard is cheaper than wooden boards, lighter, easier to install, and easier to recycle; PCC's and PMCC's many advantages make them ideal environmentally friendly soundabsorbing materials. 


\subsection{STL Results from Transmission Matrix Method}

Figure 8 shows the SLT of NPCC, PCC, and PCCM in the 100-6400 Hz frequency range.

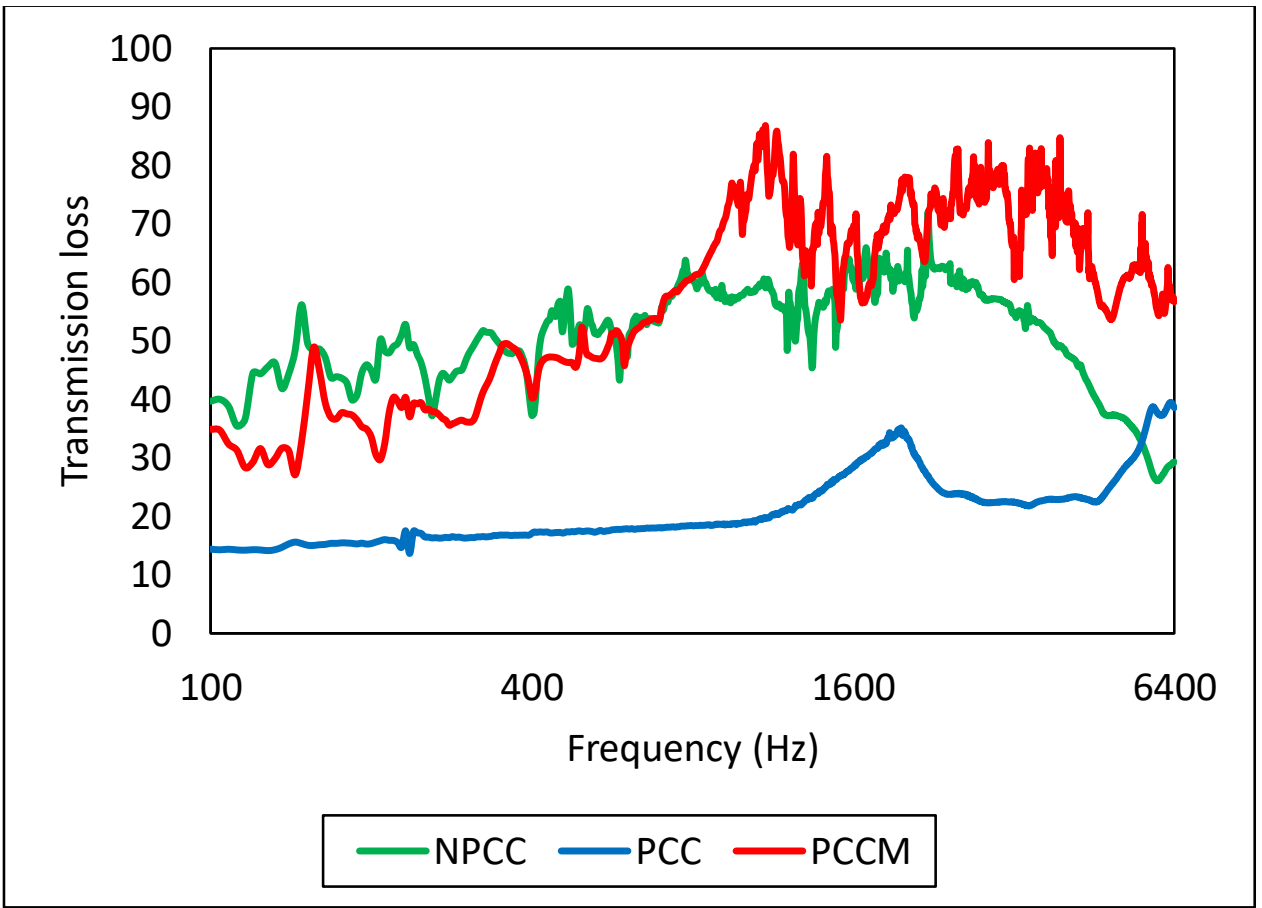

Figure 8. STL for CC, PCC, and PCCM.

The average STL of NPCC, PCC, and PCCM were 48.246 (SD 4.683) dB, 25.590 $(\mathrm{SD} 1.839) \mathrm{dB}$, and $65.011(0.878) \mathrm{dB}$, respectively.

NPCC is a good sound insulation material in itself. The PCC's STL was significantly lower than that of the NPCC due to the surface liner paper perforations. However, the PCCM also showed good sound-insulation performance because the multi-perforated corrugated cardboard on the front side and the NPCC on the rear-side block the sound energy.

Corrugated cardboard has a low specific gravity and is thick; therefore, transmission loss is generally high. As frequency increases, transmission loss decreases. Below $1000 \mathrm{~Hz}$, corrugated cardboard is a good sound-insulation material.

\subsection{Sound Pressure Level Analysis}

The average sound pressure level of the blender without a cover was 86.267 (SD 1.840) $\mathrm{dB}$, while the levels using NPCC, PCC, and PCCM were 75.500 (SD 0.432) $\mathrm{dB}, 72.133$ (SD 1.096) $\mathrm{dB}$, and 64.367 (SD 0.573) $\mathrm{dB}$, respectively (Figure 9).

NPCC application already reduced the blender's sound level pressure by $11 \mathrm{~dB}$ solely on account of its sound insulation effect. PCC application lowered the noise reduction rate by $13 \mathrm{~dB}$, and the PCCM reduced the noise by $22 \mathrm{~dB}$. There was no difference in the average SAC between the PCC and the PCCM, but the PCCM's blender noise reduction effect was greater than that of the PCC. This is because the PCCM's sound-absorption peak frequency range was similar to the blender's noise frequency range. 


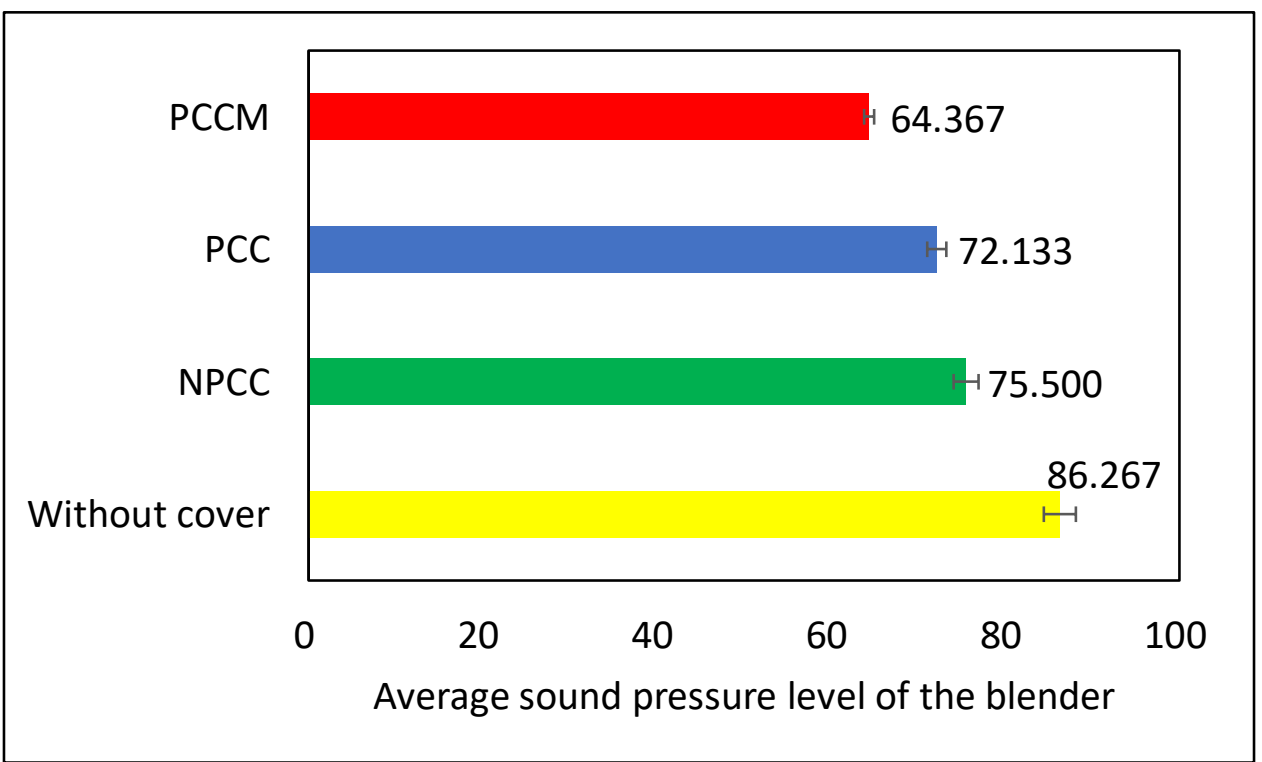

Figure 9. Sound level results of blender without cover, blender with NPCC cover, blender with PCC cover, and blender with PCCM cover.

\section{Conclusions}

The possibility of using corrugated cardboard as an eco-friendly sound-absorbing and insulating material was investigated. The material was applied to a blender to evaluate its noise reduction effect. The results of the study are as follows:

1. Corrugated cardboard itself had a sound insulation effect.

2. The NRC of PCC and PCCM were 0.346 (SD 0.007) and 0.423 (0.009), respectively. The average sound pressure level of the blender using NPCC, PCC, and PCCM were 75.500 (SD 0.432) dB, 72.133 (SD 1.096) dB, and 64.367 (SD 0.573) dB, respectively.

3. Compared with other NRC natural fiber composite board, Wooden MPP, and NPCC (parallel direction), and the PCCM demonstrated higher sound-absorption capabilities

4. PCCM shows considerable promise as a sustainable, eco-friendly sound-absorbing and insulating material.

On the basis of the findings in this study, it will be possible to develop a variety of sound-absorbing and sound-insulating materials using the method of corrugated cardboard perforation. In the low-carbon era, in which the recycling of resources has become a necessity for the sustainable future of the earth and humanity, corrugated cardboard is likely to become an increasingly valuable resource as an eco-friendly sound-absorbing material.

Author Contributions: C.-W.K.: conceptualization, investigation, methodology, writing-original draft, writing — review and editing. M.K.K.: conceptualization, methodology, supervision, writingreview and editing. E.-S.J.: experiment, data analysis, supervision, writing-original draft, writingreview and editing. All authors have read and agreed to the published version of the manuscript.

Funding: This research was supported by the Basic Science Research Program through the National Research Foundation of Korea (NRF) funded by the Ministry of Education (NRF-2019R1I1A3A02059471). It was supported under the international cooperation program framework managed by the NRF of Korea (NRF-2020K2A9A2A08000181).

Institutional Review Board Statement: Not applicable.

Informed Consent Statement: Not applicable.

Data Availability Statement: Not applicable.

Conflicts of Interest: The authors declare no conflict of interest. 


\section{References}

1. Kim, E.-S. Sound and the Korean public: Sonic citizenship in the governance of apartment floor noise conflicts. Sci. Cult. 2016, 25, 538-559. [CrossRef]

2. Szopińska, K.; Krajewska, M. Prices of apartments in relation to noise level in Poland. J. Civ. Eng. Archit. 2013, 7, 1189-1195. [CrossRef]

3. NOISEINFO. Field Diagnosis and Measurement Service of Noise. Available online: http://www.noiseinfo.or.kr/about/stats/ fieldDiagnosisSttus_02.jsp (accessed on 6 December 2020).

4. Moebus, S.; Gruehn, D.; Poppen, J.; Sutcliffe, R.; Haselhoff, T.; Lawrence, B. Acoustic quality and urban health-more than just noise and silence. Bundesgesundh. Gesundh. Gesundh. 2020, 63, 997-1003. [CrossRef]

5. Hassan, T.; Jamshaid, H.; Mishra, R.; Khan, M.Q.; Petru, M.; Novak, J.; Choteborsky, R.; Hromasova, M. Acoustic, Mechanical and Thermal Properties of Green Composites Reinforced with Natural Fibers Waste. Polymers 2020, 12, 654. [CrossRef] [PubMed]

6. Atienzar-Navarro, R.; Del Rey, R.; Jesus, A.; Sanchez-Morcillo, V.J.; Pico, R. Sound Absorption Properties of Perforated Recycled Polyurethane Foams Reinforced with Woven Fabric. Polymers 2020, 12, 401. [CrossRef]

7. Leiva, C.; Arenas, C.; Vilches, L.F.; Alonso-Farinas, B.; Rodriguez-Galan, M. Development of fly ash boards with thermal, acoustic and fire insulation properties. Waste Manag. 2015, 46, 298-303. [CrossRef]

8. Feng, L. Enhancement of low frequency sound absorption by placing thin plates on surface or between layers of porous materials. J. Acoust. Soc. Am. 2019, 146, EL141. [CrossRef]

9. Gardonio, P.; Zilletti, M. Integrated tuned vibration absorbers: A theoretical study. J. Acoust. Soc. Am. 2013, 134, 3631-3644. [CrossRef]

10. Long, H.; Cheng, Y.; Liu, X. Reconfigurable sound anomalous absorptions in transparent waveguide with modularized multi-order Helmholtz resonator. Sci. Rep. 2018, 8, 15678. [CrossRef]

11. Kim, S.; Kim, Y.H.; Jang, J.H. A theoretical model to predict the low-frequency sound absorption of a helmholtz resonator array. J. Acoust. Soc. Am. 2006, 119, 1933-1936. [CrossRef] [PubMed]

12. Iannace, G.; Trematerra, A. Acoustic measurements and correction of a council room. Noise Vib. Worldw. 2014, 45, 12-16. [CrossRef]

13. Iannace, G.; Ciaburro, G. Modelling sound absorption properties for recycled polyethylene terephthalate-based material using Gaussian regression. Build. Acoust. 2020. [CrossRef]

14. Asdrubali, F.; Schiavoni, S.; Horoshenkov, K. A review of sustainable materials for acoustic applications. Build. Acoust. 2012, 19, 283-311. [CrossRef]

15. Iannace, G.; Bravo-Moncayo, L.; Ciaburro, G.; Puyana-Romero, V.; Trematerra, A. The use of green materials for the acoustic correction of rooms. In Proceedings of the INTER-NOISE and NOISE-CON Congress and Conference Proceedings, Madrid, Spain, 30 September 2019; pp. 2589-2597.

16. Yang, H.S.; Kim, D.J.; Kim, H.J. Rice straw-wood particle composite for sound absorbing wooden construction materials. Bioresour. Technol. 2003, 86, 117-121. [CrossRef]

17. António, J.; Tadeu, A.; Marques, B.; Almeida, J.A.; Pinto, V. Application of rice husk in the development of new composite boards. Constr. Build. Mater. 2018, 176, 432-439. [CrossRef]

18. Chen, C.; Wang, Z.; Zhang, Y.; Bi, M.; Nie, K.; Wang, G. Investigation of the hydrophobic and acoustic properties of bio windmill palm materials. Sci. Rep. 2018, 8, 13419. [CrossRef] [PubMed]

19. Iannace, G.; Trematerra, A.; Trematerra, P. Acoustic correction using green material in classrooms located in historical buildings. Acoust. Aust. 2013, 41, 213-218.

20. Iannace, G.; Berardi, U.; Ciaburro, G.; Trematerra, A. Egg cartons used as sound absorbing systems. In Proceedings of the INTER-NOISE and NOISE-CON Congress and Conference Proceedings, Seoul, Korea, 12 October 2020; pp. 405-412.

21. Jang, E.-S.; Kang, C.-W.; Kang, H.-Y.; Jang, S.-S. Sound Absorption Property of Traditional Korean Natural Wallpaper (Hanji). J. Korean Wood Sci. Technol. 2018, 46, 703-712. [CrossRef]

22. Lin, L.; Yang, J.; Ni, S.; Wang, X.; Bian, H.; Dai, H. Resource utilization and ionization modification of waste starch from the recycling process of old corrugated cardboard paper. J. Environ. Manag. 2020, 271, 111031. [CrossRef]

23. Asdrubali, F.; Pisello, A.; D’Alessandro, F.; Bianchi, F.; Cornicchia, M.; Fabiani, C. Innovative cardboard based panels with recycled materials from the packaging industry: Thermal and acoustic performance analysis. Energy Procedia 2015, 78, 321-326. [CrossRef]

24. Langfeldt, F.; Hoppen, H.; Gleine, W. Resonance frequencies and sound absorption of Helmholtz resonators with multiple necks. Appl. Acoust. 2019, 145, 314-319. [CrossRef]

25. Diarte, J.; Vazquez, E.; Shaffer, M. Tooling Cardboard for Smart Reuse: A Digital and Analog Workflow for Upcycling Waste Corrugated Cardboard as a Building Material. In Proceedings of the International Conference on Computer-Aided Architectural Design Futures, Daejeon, Korea, 26-28 June 2019; pp. 384-398.

26. Schonwalder, J.; Rots, J.G. Cardboard: An innovative construction material. In Sustainable Construction Materials and Technologies; Chun, Y., Claisse, P., Naik, T.R., Ganjian, E., Eds.; Taylor \& Francis: Leiden, The Netherlands, 2007; pp. 731-740.

27. Xia, X.; Dong, Z.; Zhag, X. Study on a New Type of Hydrophobic and Moisture Proof Packaging Board and Its Performance. Packag. Eng. 2010, 31, 13-16. 
28. Cataldi, P.; Profaizer, M.; Bayer, I.S. Preventing water-induced mechanical deterioration of cardboard by a sequential polymer treatment. Ind. Eng. Chem. Res. 2019, 58, 6456-6465. [CrossRef]

29. Yang, G.; Liu, J.; Xu, B.; Liu, Z.; Ma, F.; Zhang, Q. Effect of silicon-containing nitrogen and phosphorus flame-retardant system on the mechanical properties and thermal and flame-retardant behaviors of corrugated cardboard. J. Anal. Calorim. 2020. [CrossRef]

30. Berardi, U.; Iannace, G. Acoustic characterization of natural fibers for sound absorption applications. Build. Environ. 2015, 94, 840-852. [CrossRef]

31. Kang, C.; Seo, Y. Sound absorption and sound transmission loss of perforated corrugated board. J. Korea TAPPI 2018, 50, 32-39. [CrossRef]

32. Kang, C.-W.; Kim, M.K.; JANG, E.S.; Lee, Y.-H.; Jang, S.-S. Sound Absorption Coefficient and Sound Transmission Loss of Porous Sponge Attached Corrugated Cardboard of Noise Insulation Cover. J. Korea TAPPI 2020, 52, 38-44. [CrossRef]

33. Epp, S.; Konz, S. Home appliance noise: Annoyance and speech interference. Home Econ. Res. J. 1975, 3, 205-209. [CrossRef]

34. ISO11534-2. Acoustics-Determination of Sound Absorption Coefficient and Impedance in Impedance Tubes-Part 2 Transfer-Function Method; International Organization for Standardization (ISO): Geneva, Switzerland, 2001.

35. ASTM E2611-19. Standard Test Method for Normal Incidence Determination of Porous Material Acoustical Properties Based on the Transfer Matrix Method; ASTM International: West Conshohocken, PA, USA, 2019.

36. Sharma, S.; Shukla, S.; Sethy, A. Acoustical behaviour of natural fibres-based composite boards as sound-absorbing materials. J. Indian Acad. Wood Sci. 2020, 17, 66-72. [CrossRef]

37. Song, B.; Peng, L.; Fu, F.; Liu, M.; Zhang, H. Experimental and theoretical analysis of sound absorption properties of finely perforated wooden panels. Materials 2016, 9, 942. [CrossRef]

38. Mitchell, M.; Muftakhidinov, B.; Winchen, T.; Jedrzejewski-Szmek, Z. Engauge Digitizer Software. Available online: https: // markummitchell.github.io/engauge-digitizer/ (accessed on 8 April 2021). 